\title{
$\mathrm{SNS}$ 에서 지속적인 사용 의도에 영향을 미치는 요인 연구 ${ }^{+}$
}

\section{A Study on Exploring Factors Influencing Continuance Intention in the SNS}

\author{
이 문 봉* \\ (Moon-Bong Lee)
}

\begin{abstract}
요 약 SNS는 인터넷 상에서 공통의 관심사를 지니고 있는 사용자들 간의 관계형성을 지원 하고, 이렇게 형성된 지인관계를 바탕으로 인맥관리, 정보 및 컨텐츠 공유 등 다양한 활동을 할 수 있도록 지원하는 서비스를 말한다. 본 연구의 목적은 SNS에서 지속적인 사용 의도에 영향을 미치는 요인을 파악하는 것이다. 이를 위해 정보시스템 사후-수용 모델과 성공모델을 이용하여 연구 모형을 설정하여 275 명의 대학생들을 대상으로 실증분석하였다. 그 결과는 첫째, 만족과 인 지된 유용성이 지속적 사용 의도에 정 $(+)$ 의 영향을 미치는 것으로 나타났다. 둘째, 기대일치, 시 스템 품질, 정보 품질, 인지된 유용성은 만족에 정 $(+)$ 의 영향을 미치는 것으로 나타났다. 셋째, 기 대일치는 인지된 유용성에 정(+)의 영향을 미치는 것으로 나타났다. 넷째, 시스템 품질과 정보 품 질은 기대일치에 정 $(+)$ 의 영향을 미치는 것으로 나타났다. 마지막으로, 지속적 사용 의도에 가장 큰 영향을 미치는 요인은 만족으로 나타났고, 만족에 가장 큰 영향을 미치는 것은 인지된 유용성 이었다.
\end{abstract}

핵심주제어 : 소셜 네트워크 서비스, 기대일치이론, 사후-수용 모델, 지속적 사용 의도, 만족, 기대일치, 인지된 유용성, 정보 품질, 시스템 품질

Abstract Social Network Service is a web-based service that allows the people to construct relationship among users with same interest and supports various activities such as managing personal relations and sharing information or contents. Based on the IS Post-Acceptance model and Success Model, this study examines factors influencing the continuance intention in the SNS. Questionnaires are collected from 275 students who are using the SNS. The results are following: first, the perceived usefulness and satisfaction have positive effect on the continuance intention. Second, the perceived usefulness, confirmation, system quality and information quality have positive effect on the satisfaction. Third, the confirmation has positive effect on the perceived usefulness. Fourth, the system quality and information quality have positive effect on the confirmation. Fifth, the satisfaction is the strongest predictor of the continuance intention and the perceived usefulness is the strongest predictor of the satisfaction.

Key Words : Socal Network Service, Expectation-Confirmation Model, Post-Acceptance Model, Continuance Intention, Satisfaction, Confirmation, Perceived Usefulness, Information Quality, System Quality

† 이 논문은 2011학년도 동의 대학교 교내연구비 지원(과제번호 2011AA074)에 의하여 연구되었음.

* 동의대학교 경영정보학과 부교수 


\section{1. 서 론}

정보통신기술의 발달에 따른 인프라와 소프트웨어의 발전과 함께 인터넷의 사용이 보편화됨으로써 인터넷 을 이용하여 전 세계의 수많은 정보에 접근하고 이용 하는 것이 가능하게 되었고, 집단간 혹은 개인간 커뮤 니케이션이 가능하게 되었다. 최근에 각광을 받고 있 는 소셜 네트워크 서비스(Social Network Service; 이 하 $\mathrm{SNS}$ )는 인터넷을 기반으로 사람과 사람을 연결하 고 정보공유, 인맥관리, 자기표현 등을 통해 타인과의 관계를 관리할 수 있는 서비스로서, 개인간 커뮤니케 이션을 촉진하고 사회적 네트워크 형성을 가능하게 하 여 정보 컨텐츠를 생산, 소유, 공유, 소비하는 공간으 로 빠르게 진화하고 있으며, 모바일 혁명을 통해 서비 스의 영역이 확산되고 있는 추세에 있다. 페이스북 (Facebook), 싸이월드(Cyworld), 마이스페이스(Myspace) 와 같은 $\mathrm{SNS}$ 는 사용자로 하여금 그룹을 만들거나 기 존 그룹에 가입하게 함으로써, 유사한 관심사를 가진 다른 사람들과 상호작용할 수 있도록 하고 있으며, 트 위터(Twitter)는 대표적인 모바일용 SNS로 스마트 폰 의 보급으로 최근 각광을 받고 있는 서비스이다. 한국 인터넷 진흥원과 방송통신위원회의 2010년 인터넷 이 용실태 조사 보고서에 따르면 인터넷 사용자의 $65.7 \%$ 가 소셜 네트워크 서비스를 이용하고 있으며, 10 대, 20 대, 30 대가 대다수를 차지하고 있으며, 40 대도 $50 \%$ 에 이르는 사용률을 보이고 있다. $\mathrm{SNS}$ 를 사용하는 사람 들은 증가하고 관련 연구도 이루어지고 있지만, $\mathrm{SNS}$ 를 사용하려는 심리학적인 과정을 파악하는 연구나 [13], SNS 사용에 영향을 미칠 수 있는 인지적 혹은 행동적 요인에 관한 연구는 아직까지 부족한 상황이다 [14].

정보시스템 분야에서 많은 연구자들이 정보기술의 이용을 설명하는데 있어, 사람들의 의사결정 과정에서 의 인지적 또는 행위에 중점을 두어 왔다. 새로운 정 보기술의 수용과 확산과 관련한 대다수의 연구들에서 는 개인의 사전 수용 활동과 수용 의사결정, 그리고 초기 사용과 관련한 인지적 처리과정에 초점을 맞추 어 왔다[15]. 하지만, 이러한 초기의 사용도 중요하지 만 보다 중요한 것은 계속적으로 사용하는 것이 보다 중요할 것이다. 즉, 아무리 가치가 높은 사이트라도
사용자들이 지속적으로 사용하지 않는다면 그 사이트 는 회원을 잃게 될 것이고 결국 실패하게 될 것이다. 특히 현재와 같은 치열한 경쟁 환경 하에서 생존을 위한 지속적인 경쟁 우위를 확보하기 위해서는 지속 적인 사용의도를 높여야 한다. 최근에서야 이러한 지 속적 사용 의도의 중요성을 인지하고 몇몇 연구[1],[2] 에서 지속적 사용 의도에 영향을 미치는 요인을 분석 하였다. 정보기술의 지속적 사용 행위는 혁신확산 이 론에 의하면 수용 이후의 단계에서 발생되며, 이는 해 당 정보기술의 사용 경험을 전제하고 있다[16]. 즉 수 용 과정에서의 만족은 정보기술의 지속적 사용여부에 중요한 영향을 미치는 요인이다.

사람들이 $\mathrm{SNS}$ 를 계속적으로 사용하는 이유는 과연 무엇일까? 본 연구는 사용자들이 $\mathrm{SNS}$ 를 지속적으로 사용하려는 의도에 영향을 미칠 수 있는 요인을 파악 하는 것이 목적이다. 이를 위해 정보시스템의 지속적 사용 의도를 설명하는 대표적인 이론 중의 하나인 기 대일치 이론(Expectation-Confirmation Theory; ECT) 에 기반한 사후-수용 모델(Post-Acceptance Model)과 정보시스템 성공 모형을 이용하여 지속적 사용 의도 에 영향을 미치는 요인을 파악하고, $\mathrm{SNS}$ 를 사용하고 있는 대학생들을 대상으로 실증분석해 보고자 한다.

\section{2. 이론적 배경}

\subsection{SNS(Social Network Services)}

$\mathrm{SNS}$ 란 인터넷 상에서 공통의 관심사를 지니고 있 는 사용자들 간의 관계형성을 지원하고, 이렇게 형성 된 지인관계를 바탕으로 인맥관리, 정보 및 컨텐츠 공 유 등 다양한 활동을 할 수 있도록 지원하는 서비스 를 말하는 것[17]으로서 기존의 가상 커뮤니티, 블로그 등과 같이 공통의 관심사를 공유하거나 특정한 가상 모임에서 자신의 의견을 게재하고 토론하는 방식의 서비스와 비슷한 의미를 지니고 있다. 기존 인터넷 기 반의 블로그와 페이스북, 동영상을 생산 - 공유하는 유 튜브에 이어 모바일에서 활용이 돋보이는 트위터 등 과 같은 다양한 소셜 미디어가 확산되면서 최근 각광 을 받고 있다[3]. 이러한 $\mathrm{SNS}$ 는 사용자 개개인이 중 
심이 되어 사용자들 간의 관계를 형성하고 사용자들 간의 관계가 축적되어 하나의 네트워크를 형성하게 된다는 점에서 기존의 가상 커뮤니티 서비스와는 차 별화되는데, 최근 아이폰과 같은 스마트 폰의 보급과 트위터 열풍으로 인해 상당히 각광받는 소통의 수단 으로 여겨지고 있다[4]. 기존 $\mathrm{SNS}$ 관련 연구를 통해 발견된 사실은 사용자들이 사회적 관계를 형성하기 위해 두 가지 방법으로 SNS를 사용하는데, 첫 번째는 유사한 관심사를 가진 타인을 찾는 것이고[18], 두 번 째는 기존에 알고 있던 지인들과의 관계를 계속 유지 하기 위해서 사용한다[19]. 온라인에서 처음으로 형성 된 관계가 실제 오프라인 접촉으로 연결되는 경우가 많으며, SNS를 통해 일단 관계가 형성된 이후에는 면 대면 방법보다 더 강하고, 심도 있는 장기간 관계로 발전될 수 있다.

국내는 1999년 동창 찾기를 위한 아이러브스쿨이 오픈한 이후 카페, 미니홈피, 블로그로 이어지다가 2009년부터는 마이크로 블로그 시대로 넘어가고 있다. 특히 우리나라의 싸이월드는 2006년 5월 미국과 대만 에 이어 유럽까지 진출했던 SK커뮤니케이션즈의 돋보 이는 비즈니스 모델로 세계적 주목을 끌었던 서비스 모델이었다. 일촌, 도토리라는 생소한 용어를 등장시켰 으며 소액이 모여 거액이 되는 것을 보여주었다. 도토 리라는 용어는 한국인에게 거부감을 줄일 수 있었고, 지금까지 인터넷은 모든 것이 공짜라는 인식을 전환 시키는 계기가 된 중요한 전환점이다[5]. 기존의 SNS 가 유선 서비스 중심이었다면, 앞으로는 무선 (wireless) 또는 모바일 SNS의 형태로 발전하게 될 것은 당연할 것으로 예상되며, 컨텐츠의 생산, 유통, 소비 모두 모바일기기를 중심으로 이루어질 것으로 전망되고 있다.

\section{2 정보시스템의 지속적 사용}

정보시스템 도입은 정보시스템 성공의 중요한 첫 단계이다. 그러나 정보시스템의 지속적 생명력과 궁극 적인 성공은 최초의 도입보다는 지속적 이용에 달려 있다[16]. 왜냐하면 정보시스템의 사용빈도가 낮고 사 용방법이 적절치 못하고, 사용의 효과가 없는 경우에 는 해당 정보시스템의 도입은 실패로 단정되기 때문
이다. 따라서 조직의 정보시스템의 지속사용은 도입이 아닌 활성화의 문제로 이해되며[6], 또한 기업은 지속 적인 경쟁우위를 확보하기 위해 지속적인 이용의도를 높이는데 관심을 두고 있기에 지속적인 사용은 시스 템의 성공과 결부되어있다고 볼 수 있다. 정보시스템 의 도입이나 채택 혹은 정보기술 서비스 및 제품의 수용에 대한 연구는 다양하게 이루어진 반면, 수용 이 후에 사용자의 지속적 사용의도에 대한 연구는 일부 선험적인 연구들 이후에 최근에서야 그 중요성에 입 각하여 조금씩 연구가 진행되어 오고 있다. 정보시스 템의 수용 이후의 지속 사용의 연구 중 대표적인 이 론은 ECT로 소비자 만족, 구매 후 행동(재구매나 불 평 등), 그리고 서비스 마케팅을 연구하는 소비자 행 동 연구에서 폭넓게 사용되는 이론이다. 제품을 재구 매하거나 서비스를 계속 사용하려는 소비자의 의도는 해당 제품이나 서비스의 사용에 대한 만족에 의해 결 정된다. 즉, 구매나 사용 만족 혹은 불만족에 대한 사 용자의 평가는 구매나 사용이전의 기대 성과와 사용 경험을 토대로 한 실제 성과 간의 일치 정도에 대한 비교를 통해 이루어지는 것으로 설명하고 있다[20].

Bhattacherjee[16]는 ECT와 기술수용모형을 기반으 로 <그림 1>의 정보시스템 사후-수용 모델을 제시하 였고, 온라인 뱅킹 사용자들을 대상으로 실증적으로 분석하였다. 이 모델에서 무엇보다 중요한 것은 사전 기대와 실제 사용 결과와의 차이를 사용자가 경험적 으로 평가하는 기대일치(Confirmation)라는 구성개념 을 활용하고 있다는 것이다. 이 기대일치는 사용자의 실제 사용 경험을 통해 얻어지며, 나아가 지속적인 사 용을 결정하는 인지된 유용성과 만족에 영향을 미친 다는 점이다.

지속적 사용 의도의 영향 요인에 관한 연구를 살펴 보면, 만족이 사용자의 지속적인 사용 의도에 주요한 선행요인으로 나타났다[21][22][7]. 이외에도 사용자 습 관[23], 몰입[24], 사용자 참여[1], 서비스 품질과 전환 비용[2], 애착[8] 등도 사용자의 지속적 사용 의도에 직 - 간접적인 영향을 미치는 것으로 나타났다. 


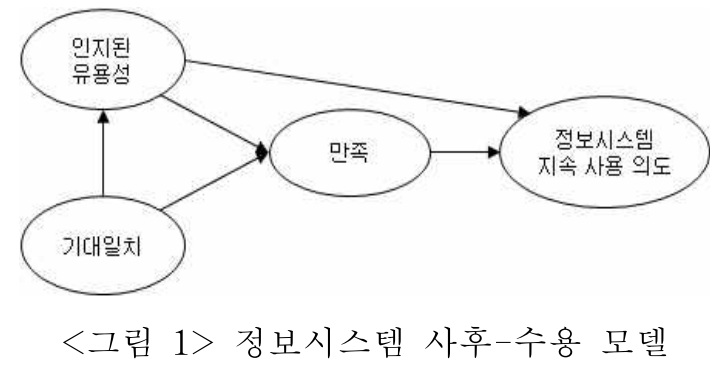

\section{3 정보시스템 성공 모형}

Delone and McLean[26]은 정보시스템 성공요소에 대한 기존 연구를 통합하여 시스템 품질, 정보 품질, 사용, 만족, 개인 성과, 그리고 조직 성과의 6가지 성 공요인을 도출하였다. 이 연구는 정보시스템 성공 모 형의 실증적, 이론적 연구 기초를 마련했다는 점에서 그 의의가 있다. 정보시스템이 발전하고 기업내의 역 할이 증가함에 따라 정보시스템의 성공을 위해서는 정보시스템 자체의 성과뿐만 아니라 서비스 부분의 중요성도 점차 증가하게 되었다. 이에 따라 Pitt et al.[27]은 정보시스템 성공 모형에 서비스 품질이 추가 되어야 함을 제안하였다. Delone and McLean[28]은 10 년동안 많은 연구자들이 제시한 개념과 정보시스템 의 기업내 역할과 관리에 있어서의 변화를 감안하여 전자상거래 환경을 고려한 수정된 성공 모형을 제시 하였다. 기존의 성공 모형에 서비스 품질을 추가하고, 사용의 모호한 성격을 특정 상황에 따라 사용 의도의 개념으로 대체할 수 있고, 개인 성과와 조직 성과를 성과로 통일함으로써 성공 모형을 수정하여 제시하였 다. 정보시스템 성공 모형에 의하면 만족에 영향을 미 치는 중요 요인은 정보 품질, 시스템 품질, 서비스 품 질이다.

\section{3. 연구 방법}

\section{1 연구 모형}

SNS 이용자들은 자신이 사용하고 있는 SNS에 만 족하고 있기 때문에 계속 사용하고 있다고 볼 수 있 다. 본 연구의 목적은 SNS의 지속적 사용 의도에 미 치는 영향을 분석하는 것이다. 이를 위해 정보시스템
사후-수용 모델과 정보시스템 성공 모형을 통합하여 <그림 2>와 같은 연구 모형을 설정하였다.

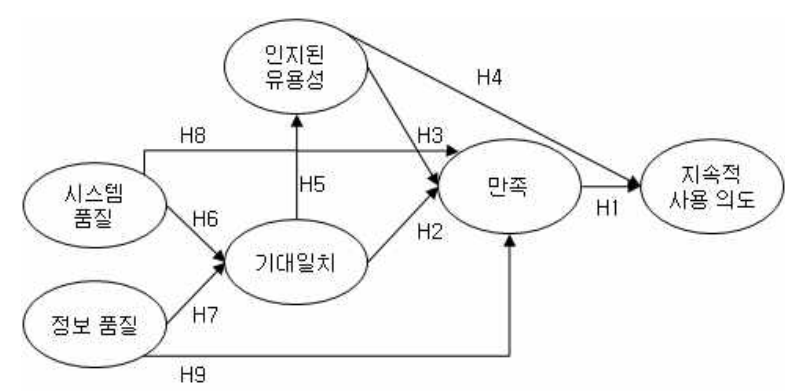

<그림 2> 연구 모형

지속적 사용 의도에 영향을 미치는 요인으로 만족을 설정하였고, 만족의 선행 변수로 정보시스템 사후-수 용 모델에서 사용된 기대일치와 인지된 유용성 변수와 정보시스템 성공 모형에서 사용된 품질 요인 중 $\mathrm{SNS}$ 에서 중요하다고 판단되는 시스템 품질과 정보 품질 변수를 추가하였다. 또한 몇몇 기존 연구[29][30]에서 품질 변수를 인지된 성능(Perceived Performance)의 대체 변수로 취급하여 기대일치의 선행 변수로 설정하 였기 때문에 본 연구에서도 시스템 품질과 정보 품질 을 기대일치의 선행 변수로 설정하였다.

\section{2 연구 가설}

(1) 만족

정보기술의 지속적 사용에 있어 가장 많이 사용되 어온 변수 중의 하나가 바로 만족이다. 만족은 사용자 가 SNS를 사용함으로써 느끼는 만족 수준을 말한다. 정보기술의 지속적 사용에 대한 의사결정과정에는 현 재 사용하는 정보기술에 대한 평가 중에서 만족 여부 가 중요한 역할을 담당하게 되며, 이용 과정상에 기대 미충족이 발생되면 이용을 중단하고 이를 대체할 수 있는 새로운 정보기술로 전환하게 된다. 이러한 정보 기술 이용에 따라 형성된 만족은 해당 정보기술의 지 속적인 이용 혹은 충성도 등에 영향을 미치는 주요 요인으로 볼 수 있다. 인터넷 뱅킹의 지속적 사용에 있어 만족의 역할을 살펴본 Bhattacherjee[16]의 연구, Web Portal 상황에서 계속적 이용의도에 영향을 미치 는 요인을 확인한 Lin et al.[21]의 연구, 그리고 사회 
네트워킹 사이트 이용자 지속의도 연구를 수행한 박 지홍[9] 연구 등에서 만족이 정보기술의 지속적 사용 과정에서 중요한 역할을 수행하고 있음을 확인한 바 있다. 이러한 여러 선행연구 결과에 기초를 두어 본 연구에서도 SNS 지속적 사용 의도를 설명함에 있어 만족을 중요한 변인으로 사용하여 다음과 같은 가설 을 설정하였다.

$\mathrm{H1}$ : 만족은 SNS 지속적 사용 의도에 정(+)의 영향 을 미칠 것이다.

(2) 인지된 유용성과 기대일치

인지된 유용성은 특정 응용 시스템을 사용하는 것 이 조직 내 작업성과를 향상시킬 것이라는 사용자의 주관적 확률로 정의된다[25]. 사용자들은 SNS를 사용 하면서 자신의 생활이나 업무에 필요한 유익한 정보 를 얻게 될 것이므로 $\mathrm{SNS}$ 가 유용하다고 생각할 것이 고 이는 만족과 지속적 사용 의도에 영향을 줄 것이 다. 기대수준은 사전 기대와 실제 사용 결과와의 차이 를 의미하는 것으로 정보시스템 사후-수용 모델을 구 성하는 중요 개념으로 사용자들이 SNS를 사용하기 전에 기대한 것보다 실제 사용결과가 높으면 기대일 치가 되면 사용자들은 만족하게 될 것이고, 이러한 기 대일치는 또한 사용자로 하여금 SNS가 유용하다고 생각하게 할 것이다. 인터넷 뱅킹을 대상으로 한 Bhattacherjee[16]의 연구, 이러닝을 대상으로 한 Roca et al.[30]의 연구, 모바일 인터넷 서비스를 대상으로 확장된 ECT를 검증한 Thong et al.[22]의 연구에서 인지된 유용성은 만족과 지속적 사용의도에 유의적인 영향을 미치는 것으로 나타났고, 또한 기대일치는 인 지된 유용성과 만족에 유의적인 영향을 미치는 것으 로 나타났다. 웹 포털을 대상으로 연구한 Lin et al.[21]의 연구에서는 인지된 즐거움을 확장하여 검증 한 결과 인지된 유용성이 만족에 유의적인 영향을 미 치지 못하는 것으로 나타났다. 이러한 사실을 바탕으 로 다음과 같은 가설을 설정하였다.

$\mathrm{H} 2$ : 기대일치는 만족에 정(+)의 영향을 미칠 것이다. $\mathrm{H} 3$ : 인지된 유용성은 만족에 정 $(+)$ 의 영향을 미칠
것이다.

$\mathrm{H} 4$ : 인지된 유용성은 $\mathrm{SNS}$ 지속적 사용 의도에 정 $(+)$ 의 영향을 미칠 것이다.

$\mathrm{H} 5$ : 기대일치는 인지된 유용성에 정(+)의 영향을 미칠 것이다.

(3) 시스템 품질과 정보 품질

Delone and McLean[28]의 정보시스템 성공모형에 서 시스템 품질과 정보 품질이 사용자 만족에 영향을 미칠 것이라고 가정하고 있다. 시스템 품질은 시스템 그 자체를 처리하는 정보의 측정지표를 의미하는 것 으로 속도, 안정성, 신뢰성 등으로 구성된다. 인터넷 환경에서 개인 고객을 대상으로 하는 SNS나 인터넷 뱅킹 등은 시스템의 품질에 문제가 있을 경우, 고객은 단순히 불만을 제기하거나 시정을 요구하는 차원을 넘어서 현재의 시스템 이용을 줄이거나 심지어는 포 기하고 경쟁업체의 시스템으로 변경하는 경우가 많다. 정보 품질은 정보시스템 출력물에 대한 측정지표를 의미하는데, 인터넷 환경에서 정보 및 제품과 서비스 에 대한 소비자들의 지각된 정보 품질은 소비자들의 의사결정 행동을 예측하는데 중요한 요인이 되고 있 다. Mckinney et al.[31]은 웹서비스에 대한 정보 품질 의 차원을 크게 적합성(relevance), 시의성(timeliness), 신뢰성 (reliability), 제공범위(scope), 인지된 유용성 (perceived usefulness)의 5가지로 제시하고 있다. 적 합성은 정보의 적절성, 간결성, 우수성의 정도를 의미 하고, 시의성은 정보의 적시성과 실시간 업데이트 여 부 정도를 의미하고, 신뢰성은 정보의 정확성과 일관 성의 정도를 의미하고, 제공 범위는 시스템을 통해 제 공된 정보의 범위 및 다양성의 정도를 의미하고, 인지 된 유용성은 정보를 이용하면서 사용자가 달성한 업 무 성과의 지각 정도를 의미한다. SNS 환경에 적합한 정보 품질은 5 가지 중에서 적합성과 시의성 차원이 유효하다고 판단된다. 정보시스템 성공 모형을 실증 분석한 많은 연구에서 시스템 품질과 정보 품질이 사 용자 만족에 유의적인 영향을 미친다고 밝히고 있다 [32][10]. e-러닝을 대상으로 한 Roca et al.[30]의 연 구결과 시스템 품질과 정보 품질은 기대일치와 만족 에 긍정적인 영향을 미치는 것으로 나타났다. 따라서, 
다음과 같은 가설을 설정하였다.

$\mathrm{H6}$ : 시스템 품질은 $\mathrm{SNS}$ 만족에 정 $(+)$ 의 영향을 미 칠 것이다.
본 연구에서 사용된 변수들의 조작적 정의와 설문 문항은 <표 1 >과 같이 정보시스템 관련 선행 연구들 을 중심으로 $\mathrm{SNS}$ 의 특성을 고려하여 정의하였고, 설 문 항목은 기존 연구에서 이미 검증된 것을 그대로

<표 1>변수의 조작적 정의와 설문 문항

\begin{tabular}{|c|c|c|c|}
\hline 변수 & 조작적 정의와 설문 문항 & 항목수 & 선행 연구 \\
\hline \multirow{5}{*}{$\begin{array}{l}\text { 정보 } \\
\text { 품질 }\end{array}$} & $\mathrm{SNS}$ 에서 제공하는 정보의 품질에 대한 사용자의 인식 & \multirow{5}{*}{4} & \multirow{5}{*}{$\begin{array}{l}\text { Roca et al.[30], 이문 } \\
\text { 봉[12] }\end{array}$} \\
\hline & SNS 사이트는 사용자에게 방대한 정보에 쉽고 빠른 접속을 제공한다. & & \\
\hline & SNS 사이트에서 제공하는 컨텐츠는 유용하다. & & \\
\hline & SNS 사이트를 사용함으로써 나는 많은 정보를 얻었다. & & \\
\hline & SNS 사이트에서 제공하는 컨텐츠는 아주 매력적이다. & & \\
\hline \multirow{5}{*}{$\begin{array}{l}\text { 시스템 } \\
\text { 품질 }\end{array}$} & $\mathrm{SNS}$ 시스템의 품질에 대한 사용자의 인식 & \multirow{5}{*}{4} & \multirow{5}{*}{$\begin{array}{l}\text { Delone and McLean } \\
\text { [26], Roca et al.[30], } \\
\text { 방화룡과 권순동[11] }\end{array}$} \\
\hline & 내가 이용하는 SNS의 속도는 빠른 편이다. & & \\
\hline & 내가 이용하는 SNS는 안정적인 편이다. & & \\
\hline & 내가 이용하는 SNS는 사생활이 보호되는 편이다. & & \\
\hline & 내가 이용하는 SNS는 보안이 잘되어 있는 편이다. & & \\
\hline \multirow{4}{*}{$\begin{array}{l}\text { 인지된 } \\
\text { 유용성 }\end{array}$} & $\mathrm{SNS}$ 사용으로 기대되는 혜택에 대한 사용자의 인식 & \multirow{4}{*}{3} & \multirow{4}{*}{$\begin{array}{l}\text { Bhattacherjee[16], } \\
\text { Roca et al.[30] }\end{array}$} \\
\hline & 내가 이용하고 있는 SNS는 필요한 정보를 얻는데 도움을 준다. & & \\
\hline & SNS는 내 생활에 유용하다. & & \\
\hline & SNS는 나에게 대체로 유용한 편이다. & & \\
\hline \multirow{4}{*}{$\begin{array}{l}\text { 기대 } \\
\text { 일치 }\end{array}$} & 실제 사용 결과와 기대 수준과의 차이에 대한 사용자의 인식 & \multirow{4}{*}{3} & \multirow{4}{*}{$\begin{array}{l}\text { Bhattacherjee[16], } \\
\text { Roca et al.[30] }\end{array}$} \\
\hline & $\mathrm{SNS}$ 를 사용한 경험은 기대한 것보다 좋았다. & & \\
\hline & SNS에서 제공하는 서비스 수준은 기대한 것보다 좋았다. & & \\
\hline & 전체적으로, SNS 사용에 대한 기대는 모두 충족되었다. & & \\
\hline \multirow{4}{*}{ 만족 } & $\mathrm{SNS}$ 사용에 대해 사용자가 느끼는 감정 & \multirow{4}{*}{3} & \multirow{4}{*}{$\begin{array}{l}\text { Bhattacherjee[16], } \\
\text { Roca et al.[30] }\end{array}$} \\
\hline & 나는 SNS 사용 경험에 대체로 만족한다. & & \\
\hline & 나는 SNS를 사용하면 기분이 좋았다. & & \\
\hline & 나는 SNS를 사용하면 기분이 즐거웠다. & & \\
\hline \multirow{4}{*}{$\begin{array}{l}\text { 지속적 } \\
\text { 사용 } \\
\text { 의도 }\end{array}$} & 향후 SNS를 지속적으로 사용하려는 의도 & \multirow{4}{*}{3} & \multirow{4}{*}{$\begin{array}{l}\text { Bhattacherjee[16], } \\
\text { Roca et al.[30] }\end{array}$} \\
\hline & 나는 계속적으로 $\mathrm{SNS}$ 를 사용할 것이다. & & \\
\hline & 나는 지금 현재 사용하고 있는 $\mathrm{SNS}$ 를 계속적으로 사용할 것이다. & & \\
\hline & 현재 사용하고 있는 $\mathrm{SNS}$ 를 다른 사람에게 적극적으로 추천할 것이다. & & \\
\hline
\end{tabular}

$\mathrm{H} 7$ : 정보 품질은 $\mathrm{SNS}$ 만족에 정 $(+)$ 의 영향을 미칠 것이다.

$\mathrm{H} 8$ : 시스템 품질은 기대일치에 정 $(+)$ 의 영향을 미 칠 것이다.

$\mathrm{H} 9$ : 정보 품질은 기대일치에 정 $(+)$ 의 영향을 미칠 것이다.

\section{3 변수의 조작적 정의}

사용하거나 연구의 목적에 부합되게 적절히 변형하여 사용하였다. 모든 설문 문항은 리커트 7점 척도를 사 용하여 측정하였다.

\section{4. 결과 분석}

4.1 자료 수집과 표본 특성 
본 연구에서 제안한 모형을 검증하기 위해 설문조 사 방식을 사용하였다. 이론적 배경에서 살펴보았던 선행 연구를 참조하여 설문 항목을 작성하여 부산지 역 대학생에게 2011년 10월 10일부터 10월 22일까지 13 일 동안 320 부의 설문 조사를 실시하였다. 수집된 설문 중에서 SNS를 사용하지 않는 경우와 응답 난에 연속적으로 동일한 응답을 했거나 응답 항목에 결측 치가 많은 경우는 설문분석 단계에서 제외하여 총 275 부의 유효 설문을 확보하였다. 설문 응답자의 인구 통 계학적 분석해 본 결과, 총 응답자 275 명 중에서 남자 는 159 명(57.8\%), 여자는 116 명(42.2\%)으로 나타났으 며, 학년별로는 2학년 34명(12.4\%), 3학년 101명 (36.7\%), 4학년 140명(50.9\%)으로 나타났다.

\section{2 타당성 분석과 신뢰성 분석}

본 연구에서 사용된 변수의 개념타당성을 검증하기 위해 독립 변수와 종속 변수에 대해 요인 분석을 하 였다. 그리고, 측정항목들의 내적 일관성 즉 신뢰성을 검증하기 위해 다 항목 척도간 신뢰도를 평가하는 크 론바하 알파(Cronbach's alpha) 계수를 활용하였다(한 미란 등). 일반적으로 알파 계수가 0.6 이상이면 비교 적 신뢰도가 높은 것으로 볼 수 있다[33]. 독립 변수의 타당성 분석과 신뢰성 분석 결과는 <표 $2>$ 와 같이 4 개의 독립 변수를 요인 분석한 결과 예상대로 4 개 요 인으로 잘 묶였고, 모든 항목의 요인 적재치는 0.6 이상 으로 나타났다. 알파 계수 값은 인지된 유용성 0.887 , 시스템 품질 0.805 , 정보품질 0.761 , 기대일치 0.806 으 로 나타나 비교적 신뢰성이 높다고 할 수 있다. 종속 변수인 만족과 지속적 사용 의도의 경우 기존에 많이 사용되어왔던 설문 내용으로 했기 때문에 각 요인별로 요인 분석을 한 결과 예상대로 하나의 요인으로 잘 분 류되었고, 신뢰성 검증 결과 알파 계수 값은 만족 0.870 , 지속적 사용 의도 0.888 로 비교적 높게 나타났다.

\section{3 가설 검증}

연구 모형을 기반으로 잠재변수와 측정변수를 정하 고 측정변수의 평균값의 상관관계 분석 결과를 이용 하여 공변량 구조모형에 대한 통계분석을 하였다. 연
<표 2> 독립 변수의 타당성 및 신뢰성 분석 결과

\begin{tabular}{|c|c|c|c|c|}
\hline & PU & SQ & IQ & C \\
\hline pu2 & .892 & .149 & .186 & .069 \\
\hline pu3 & .873 & .111 & .195 & .124 \\
\hline pu1 & .790 & .100 & .266 & .074 \\
\hline sq4 & .009 & .842 & .120 & .009 \\
\hline sq3 & .005 & .813 & .133 & .024 \\
\hline sq2 & .205 & .805 & .045 & .219 \\
\hline sq1 & .258 & .606 & .065 & .299 \\
\hline iq2 & .230 & .105 & .846 & .069 \\
\hline iq1 & .052 & .220 & .705 & .207 \\
\hline iq4 & .386 & .029 & .685 & .164 \\
\hline iq3 & .502 & .044 & .613 & .177 \\
\hline c2 & .025 & .078 & .173 & .842 \\
\hline c3 & .028 & .184 & .247 & .765 \\
\hline c1 & .221 & .105 & .039 & .756 \\
\hline 아이겐값 & 5.137 & 2.056 & 1.529 & 1.084 \\
\hline 설명변량 & $36.7 \%$ & $14.7 \%$ & $10.9 \%$ & $7.7 \%$ \\
\hline 크론바하 & 0.887 & 0.805 & 0.761 & 0.806 \\
\hline 알파 & & & & \\
\hline
\end{tabular}

구 모형의 적합도 지수 분석 결과 적합도는 양호한 것으로 나타났다. 일반적인 적합도 지수에 있어서도 GFI 0.91(권장수용기준 : $\geq 0.90$ ), AGFI 0.81(권장수 용기준 : $\geq 0.80$ ), NFI 0.89 (권장수용기준 : $\geq 0.90$ ) 등으로 분석되었으며, 권고하는 적합도 지수인 RMSEA 값은 0.07(권장수용기준 : $\leq 0.08$ )로 나타나 전반적인 연구 모형의 설명력은 양호한 것으로 나타났 다. 경로모형의 경로계수 검증에는 유의수준 0.05 를 기 준으로 실시하였으며, 검증 결과는 <그림 3 >과 같다.

모형의 설명력을 나타내는 $\mathrm{R}^{2}$ 값은 기대일치 0.22 , 만족 0.50 , 지속적 사용 의도 0.48 로 나타났다. 만족이 지속적 사용 의도에 정 $(+)$ 의 영향을 미칠 것이라는 가 설 1 은 T값이 9.88 로 유의수준 0.01 에서 채택되었다.

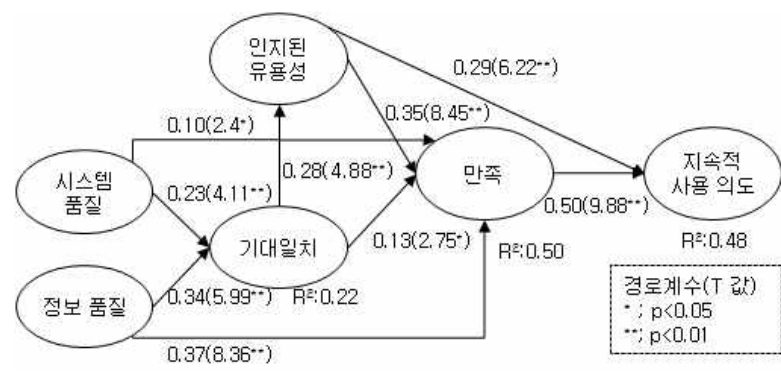

<그림 3> 가설 검증 결과 
이 결과는 만족이 지속적 사용 의도에 영향을 미치 는 주요 요인이라는 Bhattacherjee[16]와 Roca et al.[30]의 연구 결과와 동일하게 나타났다. 기대일치가 만족에 정 $(+)$ 의 영향을 미칠 것이라는 가설 2 는 $\mathrm{T}$ 값 이 2.75 유의수준 0.05 에서 채택되었고, 인지된 유용성 이 만족에 정 $(+)$ 의 영향을 미칠 것이라는 가설 3 은 $\mathrm{T}$ 값이 8.45 로 유의수준 0.01 에서 채택되었다. 이 결과 역시 기존 연구 결과와 동일하게 나타났다. 인지된 유 용성이 지속적 사용 의도에 정 $(+)$ 의 영향을 미칠 것이 라는 가설 4는 T값이 6.22로 유의수준 0.01에서 채택 되었다. 기대일치가 인지된 유용성이 정(+)의 영향을 미칠 것이라는 가설 5 는 $\mathrm{T}$ 값이 4.88 로 유의수준 0.01 에서 채택되었다. 이러한 결과 역시 기존 연구결과와 동일하게 나타났다. 시스템 품질이 만족에 정(+)의 영 향을 미칠 것이라는 가설 6 은 $\mathrm{T}$ 값이 2.4 로 유의수준 0.05 에서 채택되었으며, 정보 품질이 만족에 정 $(+)$ 의 영향을 미칠 것이라는 가설 7은 $\mathrm{T}$ 값이 8.36으로 유 의수준 0.01 에서 채택되었다. 이러한 결과는 정보시스 템 성공모형을 실증적으로 분석한 많은 연구와 동일 한 결과를 나타낸 것으로 품질 요인이 만족의 선행 변수로 중요한 역할을 하고 있다는 것을 의미한다. 시 스템 품질과 정보 품질이 기대일치에 정(+)의 영향을 미칠 것이라는 가설 8 과 9 는 $\mathrm{T}$ 값이 각각 4.11과 5.99 로 유의수준 0.01 에서 채택되었다. 이런 결과는 Roca et al.[30]의 결과와 동일하게 나타났다.

\section{5. 결 론}

본 연구에서는 $\mathrm{ECT}$ 를 기반으로 한 정보시스템 사 후-수용 모델과 정보시스템 성공 모형을 통합하여 $\mathrm{SNS}$ 를 지속적으로 사용할 의도에 영향을 미치는 요 인을 대학생들을 대상으로 실증적으로 분석하였다. 분 석 결과를 요약하면 다음과 같다. 첫째, 지속적 사용 의도에 영향을 미치는 요인은 인지된 유용성과 만족 으로 나타났다. 이 결과는 기존 연구 결과와 동일하며, 두 요인 중에서 만족이 가장 중요한 요인으로 나타났 다. 사용자들로 하여금 현재 사용하고 있는 SNS를 지 속적으로 사용하게 하는 가장 중요한 요인이 만족이 므로, 다양한 방법으로 사용자들을 만족시켜야 할 것
이다. 둘째, 만족에 영향을 미치는 요인 인지된 유용 성, 기대일치, 시스템 품질, 정보 품질로 나타났다. 인 터넷 뱅킹을 대상으로 한 Bhattacherjee[16]의 연구에 서는 인지된 유용성 보다는 기대일치가 만족에 더 큰 영향을 미치는 것으로 나타났고, $\mathrm{e}^{-}$러닝을 대상으로 한 Roca et al.[30]의 연구에서는 인지된 유용성이 보 다 더 큰 영향을 미치는 것으로 나타났다. 본 연구에 서는 인지된 유용성이 만족에 더 큰 영향을 미치는 것으로 나타났고, 시스템 품질보다는 정보 품질이 만 족에 더 중요한 요인으로 나타났다. 이는 Roca et al.[30]의 연구 결과와 동일한 것이다. 셋째, 기대일치 가 인지된 유용성에 유의적인 영향을 미치는 것으로 나타났다. 마지막으로, 시스템 품질과 정보 품질이 기 대일치에 유의적인 영향을 미치는 것으로 나타났으며, 시스템 품질보다는 정보 품질이 기대일치에 보다 더 큰 영향을 미치는 것으로 나타났다.

본 연구의 시사점은 다음과 같다. 첫째, SNS를 대 상으로 사후-수용 모델을 적용한 최초의 실증분석 연 구라는 것이다. ECT를 기반으로 한 사후-수용 모델은 인터넷 뱅킹, $\mathrm{e}^{-}$러닝, 전자상거래, 웹 포털 등을 대상 으로 많은 연구가 있었지만, SNS에 적용시켜 모델의 활용 범위를 넓혔다는데 의의가 있다. 둘째, 정보시스 템 성공 모형과 통합하여 기대일치와 만족에 영향을 미치는 시스템 품질과 정보 품질의 영향을 분석함으 로써 사후-수용 모델을 확장하였다는 것이다. 인지된 유용성과 정보 품질이 $\mathrm{SNS}$ 의 지속적 사용 의도에 중 요한 역할을 하며, 기대일치와 함께 만족의 중요한 선 행 변수라는 것이다. 그리고, 기대일치는 품질 요인과 만족 요인을 연결하는 중요한 매개 변수로서의 역할 을 셋째, 정보 품질이 기대일치와 만족에 중요한 영향 을 미치는 요인이므로 SNS 사이트 관리자는 정보 품 질에 각별히 유의하여 사용자들이 사이트를 지속적으 로 사용할 수 있도록 사용자들에게 유용하고 시의적 절한 정보를 제공하여야 할 것이다.

본 연구의 한계점 및 향후 연구 과제를 정리하면 다음과 같다. 첫째, 표본 선정에 한계가 있었다. 본 연 구는 대학생들을 중심으로 하고 있지만, SNS는 대학 생 뿐만 아니라 직장인이나 주부 등과 같이 다양한 계층의 사람들이 사용하고 있다. 따라서, 본 연구의 결과를 일반화하는데는 한계가 존재한다. 향후에는 다 
양한 집단별로 구분하여 지속적 사용 의도에 미치는 영향 관계를 분석하는 연구도 필요할 것이다. 둘째, 본 연구에서는 인지적인 측면만을 강조하여 모형을 설정하였다는 것이다. $\mathrm{SNS}$ 를 지속적으로 사용하려는 의도에 영향을 미칠 수 있는 요인은 인지적인 요인뿐 만 아니라 SNS를 실제 사용하는 행동 변수를 포괄할 수 있는 모형을 설정하여 분석하는 것도 필요할 것이 다. 셋째, 본 연구는 횡단 연구를 실시하였기 때문에 시간의 흐름에 따른 변수들의 영향을 측정할 수 없었 다. 향후 연구에서는 시계열 자료를 이용한 종단 연구 를 실시하여 모형에서 제시하는 요인들이 지속적 사 용 의도에 유의적인 영향을 미치는 지를 분석할 필요 가 있다.

\section{참 고 문 헌}

[1] 고미현, 권순동, "인터넷 커뮤니티에서 사용자 참 여가 밀착도와 지속적 이용의도에 미치는 영향", 경영정보학연구, 제 18 권 제 2 호, pp. 41-72, 2008.

[2] 신호영, 김기수, "인터넷 포털사이트 서비스의 지 속적 이용의도에 영향을 미치는 요인에 관한 연구 ", 정보시스템연구, 제 19 권, 제3호, pp. 35-58, 2010.

[3] 이동훈, 이민훈, 박성민, 이준환, “확산되는 소셜 미디어와 기업의 新소통 전략”, $\mathrm{CEO}$ Information, 삼성경제연구소, 제 764호, 2010.

[4] 고상민, 황보환, 지용구, "소셜 네트워크 서비스와 온라인 사회적 자본 : 한국과 중국 사례를 중심으 로”, 한국전자거래학회지, 제 15 권, 제 1 호, $\mathrm{pp}$. 103-118, 2010.

[5] 이동기, 김지연, "온라인 소셜네트워크 서비스 (Online Social Network Service)의 해외진출전략: SK커뮤니케이션즈 싸이월드," 경영교육연구, 제 12 권, 제3호, pp. 135-165, 2009.

[6] 이승창, 이호근, 정창욱, 정남호, 서응교, "정보시스 템 사용과 성과에 있어서 자발성의 조절효과에 관 한 연구," Asia Pacific Journal of Information Systems, pp. 195-219, 2009.

[7] 이선로, 양석원, "웹 기반 정보시스템의 지속적 사 용에 관한 통합적 연구: 인터넷 쇼핑몰 사이트를
중심으로", Journal of Information Technology Application and Management, 제16권, 제1호, pp. 51-75, 2009.

[8] 김경규, 류성렬, 김문오, 김효진, "모바일 웹 브라 우징 서비스의 사용의도에 영향을 미치는 요인: 자기효능감과 사회적 영향", Journal of Information Technology Application \& Management, 16(1), pp. 149-168, 2009.

[9] 박지홍, "사회네트워킹 사이트 이용자 지속의도에 영향을 미치는 요인에 관한 탐구", 정보처리학회 지, 제25권, 제4호, pp. 205-226, 2008.

[10] 이문봉, 강병영, "e-Learning 학습 성과에 영향을 미치는 요인 분석", 한국산업정보학회논문지, 제 12권 제5호, pp. 173-182, 2007.

[11] 방화룡, 권순동, "중국의 사회 연결망 서비스 이 용에 영향을 미치는 요인에 관한 연구", Journal of Information Technology Application and Management, 제16권, 제2호, pp. 45-63, 2009.

[12] 이문봉, "e-Learning 플로우가 학습성과에 미치는 영향", 한국산업정보학회논문지, 제 15 권, 제 1 호, pp. 85-94, 2010.

[13] O. B. Kwon and Y. Wen, "An Empirical Study of the Factors Affecting Social Network Service Use", Computers in Human Behavior, Vol. 26, pp. 254-263, 2010.

[14] B. Zhong, M. Hardin and T. Sun, "Less Effortful Thinking Leads to More Social Networking? The Associations Between the Use of Social Network Sites and Personality Traits", Computers in Human Behavior, Vol. 27, pp. 1265-1271, 2011.

[15] A. T. Guinea and M. L. Markus, "Why Break the Habit of a Lifetime? Rethinking th Roles of Intention, Habit, and Emotion in Continuing Information Technology Use", MIS Quarterly, Vol. 33, No. 3, pp. 433-444, 2009.

[16] A. Bhattacherjee, "Understanding Information Systems Continuance: An Expectation Confirmation Model," MIS Quarterly, Vol.25, No.3, pp.351-370, 2001. 
[17] D. M. Boyd and N. B. Ellison, "Social Network Sites: Definition, History, and Scholarship," Journal of Computer-Mediated Communication, Vol. 13, No. 1, pp. 210-230, 2007.

[18] T. Correa, A. W. Hinsley and H. Gil de Zuniga, "Who Interacts on the Web? The Intersection of User's Personality and Social Media Use", Computers in Human Behavior, Vol. 26, No. 2, pp. 247-253, 2010.

[19] N. B. Ellison, C. Steinfield and C. Lampe, " The Benefits of Facebook "Friends:" Social Capital and College Student's Use of Online Social Network Sites", Journal of Computer-Mediated Communication, Vol. 12, No. 4, pp. 1143-1168, 2007.

[20] R. L. Oliver, "Satisfaction: A Behavioral Perspective in the Consumer", New York: The McGraw-Hill International Editions, 1997.

[21] C. S. Lin, S. Wu and R. J. Tsai, "Integrating Perceived Playfulness into ExpectationConfirmation Model for Web Portal Context", Information and Management, Vol. 42, No. 5, pp. 683-693, 2005.

[22] J. Y. L. Thong, Se-Joon Hong \& K. Y. Tam, "The Effects of Post-Adoption Beliefs on the Expectation-Confirmation Model for Information Technology Continuance," Information Journal of Human Computer Studies, Vol. 64, pp.799-810, 2006.

[23] M. Limayem, S. C. Hirt and C. K. Cheung, "How Habit Limits the Predictive Power of Intention : The Case of Information Systems Continuance", MIS Quarter, Vol. 31, No. 4, pp. 705-737, 2007.

[24] B. Vantanasombut, M. Igbaria, A. C. Stylianou and W. Rogers, "Information Systems Continuance Intention of Web-based Applications Customers: The Case of Online Banking", Information and Management, Vol. 45, No. 7, pp. 418-428, 2008.
[25] F. D. Davis, R. P. Bagozzi and P. R. Warshaw, "Extrinsic and Intrinsic Motivation to Use Computers in the Workplace," Journal of Applied Social Psychology, Vol. 22, Issue 14, pp. 1111-1132, 1992.

[26] M. H. Delone and E. R. McLean, "Information System Success: The Quest for the Dependent Variable", Information Systems Research, Vol. 3, pp. 60-95, 1992.

[27] L. F. Pitt, R. T. Watson and C. B. Kavan, "Service Quality: A Measure of Information Systems Effectiveness, MIS Quarterly, Vol. 19, No. 2, pp. 173-187, 1995.

[28] M. H. DeLone and E. R. McLean, "The Delone and McLean Model of Information System Success: A ten-year Update", Journal of Management Information Systems, Vol. 19, No. 4, pp. 9-30, 2003.

[29] M. H. Hsu, Y. L. Chen and C. M. Chiu, "Examining thw WWW continuance: An Extended Expectation Confirmation Model", Communications of the ICISA, Vol. 5, No. 2, pp. 12-25, 2003.

[30] J. C. Roca, C. M. Chiu and F. J. Martinez, "Understanding e-learning Continuance Intention: An Extention of the Technology Acceptance Model", Internation Journal of Human-Computer Studies, Vol. 64, pp. 683-696, 2006.

[31] V. McKinney, Kanghyun Yoon and F. M. Zahedi, "The Measurement of Web- Customer Satisfaction: An Expectation and Disconfirmation Approach, Information Systems Research, Vol. 13, No. 3, pp. 296-315, 2002.

[32] L. Juhani, "An Empirical Test of the Delone -Mclean Model of Information System Success", The DATA BASE for Advances in Information Systems, Vol. 36, No. 2, pp. 8-27, 2005.

[33] J. C. Nunally. Psychometric Theory (2nd ed.), 
New York: McGraw Hill, 1976.

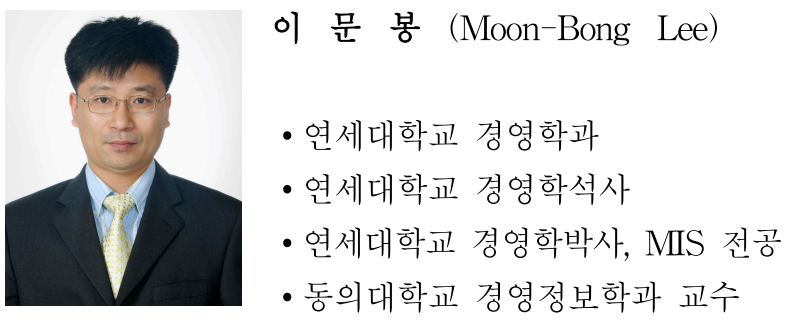

- 관심분야 : e-Learning, 온라인 커뮤니티 \& SNS, 스마트폰, 정보시스템 성과, $\mathrm{ERP}$, 클라우딩 컴퓨팅 